\title{
Hormesis in Health and Disease: Molecular Mechanisms
}

\author{
Anna Meiliana ${ }^{1,2, *}$, Andi Wijaya ${ }^{1,2}$ \\ ${ }^{1}$ Postgraduate Program in Clinical Pharmacy, Padjadjaran University, Jl. Eijkman No.38, Bandung, Indonesia \\ ${ }^{2}$ Prodia Clinical Laboratory, Jl. Cisangkuy No.2, Bandung, Indonesia \\ *Corresponding author. E-mail: anna.meiliana@prodia.co.id
}

Received date: Jun 18, 2020; Revised date: Oct 5, 2020; Accepted date: Oct 7, 2020

\section{Abstract}

$\mathrm{B}$ ACKGROUND: Hormesis was initially defined as a phenomenon where a small dose of harmful agent exposure to living organisms gives beneficial effects. The dose and time of this 'tress' exposure has become the object of investigation across the broad range of biomedical studies.

CONTENT: Hormesis characterized by the biphasic doseeffect or time-effect relationship for any substance. Some hormetic mechanisms performed biological plasticity, involve oxidative damage which instead induce antioxidant enzyme production in various cells. Early-life stress can increase resilience in later life and lack of stress can lead to vulnerability. Many stressors like dietary factors and natural environmental toxins can be occupied for healthy growth or

\section{Introduction}

'What doesn't kill you makes you stronger'. The ear-friendly aphorism illustrated the original idea of hormesis, which involved an initial exposure to induce an adaptive response before it can be referred to as 'stress-response' hormesis.(1) At a glance hormesis seems like counterintuitive, but in a deeper philosophical thinking, if 'too much of a good thing is a bad thing', a little bad thing can be good. At a precise dose and time, we can transform an adverse effect into a favorable effect, as articulated in the philosophy of Yin and Yang that 'illness is the doorway to health'.

The hormesis scenario involves three factors: first, the initial stress exposure that 'tries to kill you'; second, the following exposure which you are more resilient against; and third, the time interval between those two. homeostasis, which exemplifies how illness is the doorway to health.

SUMMARY: Hormesis reconcile many paradoxical phenomena exert opposite effects of the same substance, either a xenobiotic or an endogenous substance, a hormone or a metabolite, a genetic manipulation or an epigenetic alteration, an experimental intervention or a natural event. Human bodies are highly adaptive. A resilient body would be resulted after the 'training'. In this review, we will elucidate the hormesis' definition, mechanisms and pathways, and also how hormesis impacts in human health and lifespan.

KEYWORDS: biphasic, cell signaling, dose response, hormesis, preconditioning

Indones Biomed J. 2020; 12(4): 288-303

The initial dose low-dose exposure may protect against the following exposure of the same substrate in a higher dose ('single mode' stress-response), against a different substance ('cross-mode' stress-response), or may develop a process in the interval time ('developmental' stressresponse).(2) A classic example of single-mode stressresponse hormesis is priming the body with an initial low dose of xenobiotic chemical to induce the expression of detoxification enzymes, which can confer protection against subsequent exposures to the same chemical in a higher dose. Some xenobiotic chemicals serve directly as ligands for nuclear receptors such as the constitutive androstane receptor (CAR) or pregnane X receptor (PXR). Some other indirectly activate other transcription factors, for example altering the intracellular stress-response signaling pathways such as redox status, to activate the nuclear factor erythroid 2-related factor 2 (Nrf2). The transcription factors activation 
will upregulate the genes that encode the enzymes for xenobiotic metabolism in three phases. Phases I including cytochrome p450 family enzymes, phase II is glutathionebased conjugation enzymes, and phases III is adenosine triphosphate (ATP)-binding cassette transporters. Those three phases collectively detox and secrete the xenobiotic from the body.(3)

The dose response concept is central to biology, medicine, and public health. It represents the biological integration of how living systems at all levels of organization (from the cell, more complex organisms, human being) respond, adapt or fail to adapt to endogenous agents, metabolic stress, and externally dynamic threats/stressors. (4-6) The substance's dose-effect or time-effect relationship was presented in a bell-like biphasic curve, either U-shape or inverted U-shape $(2,7)$, describe the portion of the doseresponse immediately below the threshold which is related to performance, contrast to the portion of the dose-response above the threshold, which have the potency of toxic interactive effects. Hormetic dose-response can occur as a direct stimulation response, a modest overcompensation response after an initial disruption in homeostasis, or as a response to an 'adapting' or 'pre- conditioning' dose followed by an extensive challenging dose.(8)

In the broadest sense, everything can be hormesis. The term often used to describe a paradoxical low-dose beneficial effects of stressors. The paradox arises due to our own preconception about what is good and bad, and we often cognitively biased towards the monotonic causeeffect relationships. The hormetic dose-response model is apparently the most fundamental and very common in the biological and biomedical sciences, across biological model, endpoint measured and chemical class and physical agent. (7) In this review, we will elucidate the hormesis definition, mechanisms and pathways, and also how hormesis impacts in human health and lifespan.

\section{Defining Hormesis}

The term hormesis first coined in 1943 by Chester Southam and John Ehrlich after their observation on low concentration Red Cedar tree extract benefit in enhancing the metabolism of fungal species.(9) The definition later been revived by Edward Calabrese.(10) Many variants have been grown of its exact meaning. In general, the term hormesis related to the dose-response relationships of treatments, including chemical, thermal, or radiological which are beneficial at a low level but harmful at a higher level. However, some studies involve brief stress exposure to induce mechanisms that protect against stress. This form of hormesis refer as 'stress-response hormesis' to distinguish it from hormesis in the broader sense.(1) For example, a brief exposure to very high levels of oxygen increase life span in the nematode Caenorhabditis elegans.(11)

The most consistent and reliable character of the hormetic dose-response is its biphasic feature, i.e., a low dose stimulation zone, followed by a higher dose with inhibitory response (Figure 1). The maximum magnitude of the stimulatory response is typically modest, being only about $30-60 \%$ above that of the control response. The strong majority of stimulatory responses are less than twice the control value.(7) The Hormesis concept suggested that dose responses in the low dose zone were not only not linear but possibly not even a threshold but probably biphasic (i.e., $\mathrm{J}$-shaped or inverted U-shaped depending on the endpoint graphed).

Figure 2 proposed the nomenclature for hormesis that recognizes the classic hormetic-like biphasic dose \pm response relationships, and the temporal hormesis which also include the duration of exposure. $(12,13)$ The classic definition of hormesis is more common in the fields of radiation biology/health physics and ecological and human toxicology. Adaptive response of temporal hormesis could result from direct stimulation hormesis (DSH), or as the compensatory biological processes after initial disruption in homeostasis or overcompensation stimulation hormesis (OCSH)).(10)

Calabrese and Baldwin $(10,14)$ defined hormesis as an adaptive biphasic response, i.e., OCSH. Therefore, the adaptive response of hormesis can be low, no response at an intermediate level, then a second response at a high level of deviation from homeostasis, described in a U- or J-shaped response.(10) In other words, a low to moderate

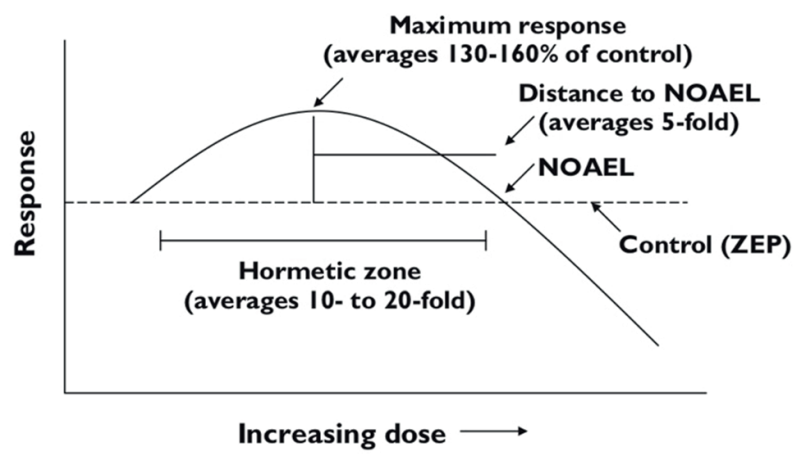

Figure 1. Dose-response curve showing the quantitative features of hormesis. NOAEL: No-observed-adverse-effect level; ZEP: Zero equivalent point.(7) (Adapted with permission from John Wiley and Sons). 


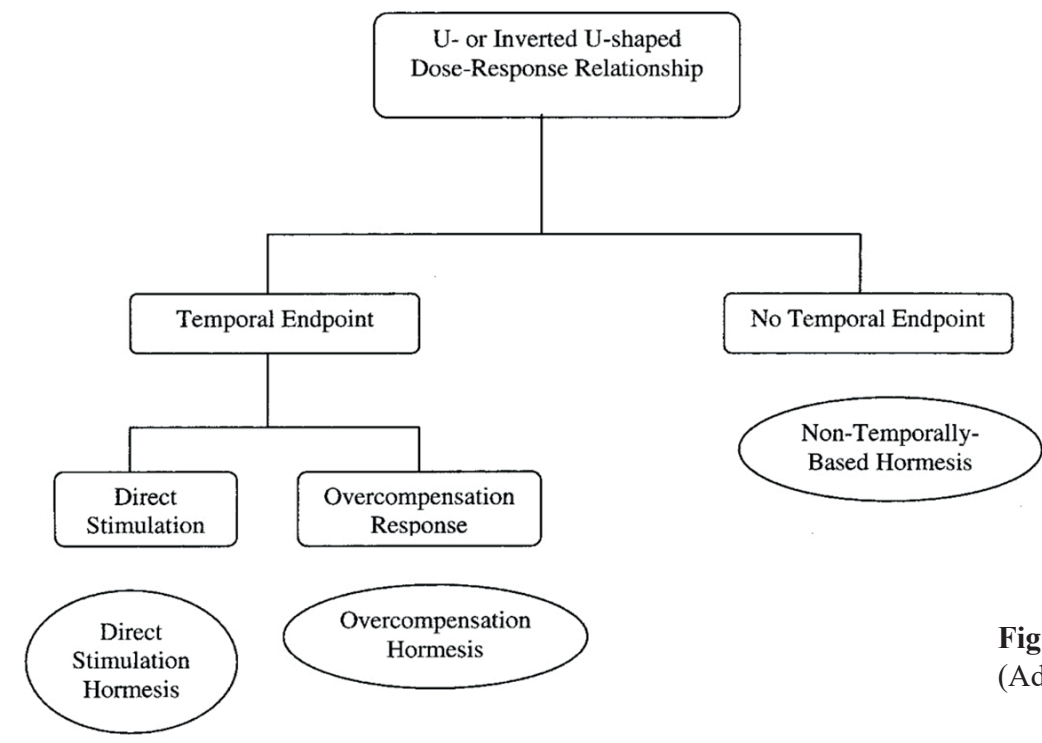

Figure 2. Schematic of hormetic nomenclature.(10) (Adapted with permission from SAGE Publication).

levels of acute stress alerts multicellular organisms, disrupt and trigger a slight overcompensation before it return to homeostasis. The natural explanation for the biphasic response is either ignores the conventional dose response, or due to a different mechanism for the response. $(10,15,16)$

\section{Hormetic Mechanisms}

The hormetic dose/concentration response relationship has attracted many researchers from a broad range in biological and biomedical disciplines, seen from the markedly increased peer-reviewed scientific literatures over the past two decades $(10,17,18)$, bring up hormesis as a highly generalizable, independent of biological model, endpoint measured, inducing agent and level of biological organization (e.g., cell, organ, organism).(19)

It's not easy to provide one clear mechanism on hormesis, since more than 100 agents and signaling pathways involved in almost 400 dose/concentration responses from a wide range of chemical classes, with a broad range of endpoints. However, a general mechanism must underlie those all. Vast range of mechanisms mediate hormetic responses 400 different hormetic dose response relationships at the level of receptor and cell signaling pathways. $(19,20)$ Hormetic-like biphasic dose/concentration responses occur by a single agonist which act via two different receptor subtypes, that antagonistic mediated the stimulatory and inhibitory pathways.(21) Receptor with high affinity to the agonist but have lower capacity (fewer receptors) mediate the stimulation, and receptor with lower affinity but have a greater capacity mediate the inhibitory response.(2225) From this concept, numerous receptors that mediated biphasic dose/concentration responses were identified since 1980 s with many examples that conformed to the hormetic dose/concentration response quantitative features.(23,24) The mechanism involving a complex and integrative array of signal transduction pathways. A part of these pathways, the relationship to the cell membrane and membrane receptors, and the inter-connections among the signaling pathways described in Figure 3.(26) Hormesis employed the same mechanisms to yield a response, either mediated by cell signaling or by any receptor. The experiment on finding which pathway is mediating the hormesis response performed by blocking a specific cell signaling pathway and see if it prevents the hormetic stimulation.

There are three types of hormetic dose/concentration response mechanisms for signaling pathways, based on their pathways for stimulation and inhibition. First, low dose stimulation and higher dose inhibition were mediated by the same receptor; second, the receptor only mediated the stimulation and the inhibition mediated by another subtype of receptor; or third, the stimulation and inhibition do not share the same family of receptor, or happen in different mechanisms. Despite these differences in mechanistic strategies the quantifiable features of the dose/concentration responses are similar, suggesting a similar functional and adaptive strategy.(19) A lot of hormetic dose response with end point of cell proliferation was mediated via mitogen activated protein kinase (MAPK)-extracellular-signalregulated kinase (ERK)1/2 cell signaling pathway (Figure 4), counted about 14 different cell types, except V79 cells in which p38 was essential whereas ERK1/2 involvement was absent. Meanwhile, when the same cell type have the hormetic dose responses for cell migration, it is typically mediated via a different cell signaling pathway such as p38 


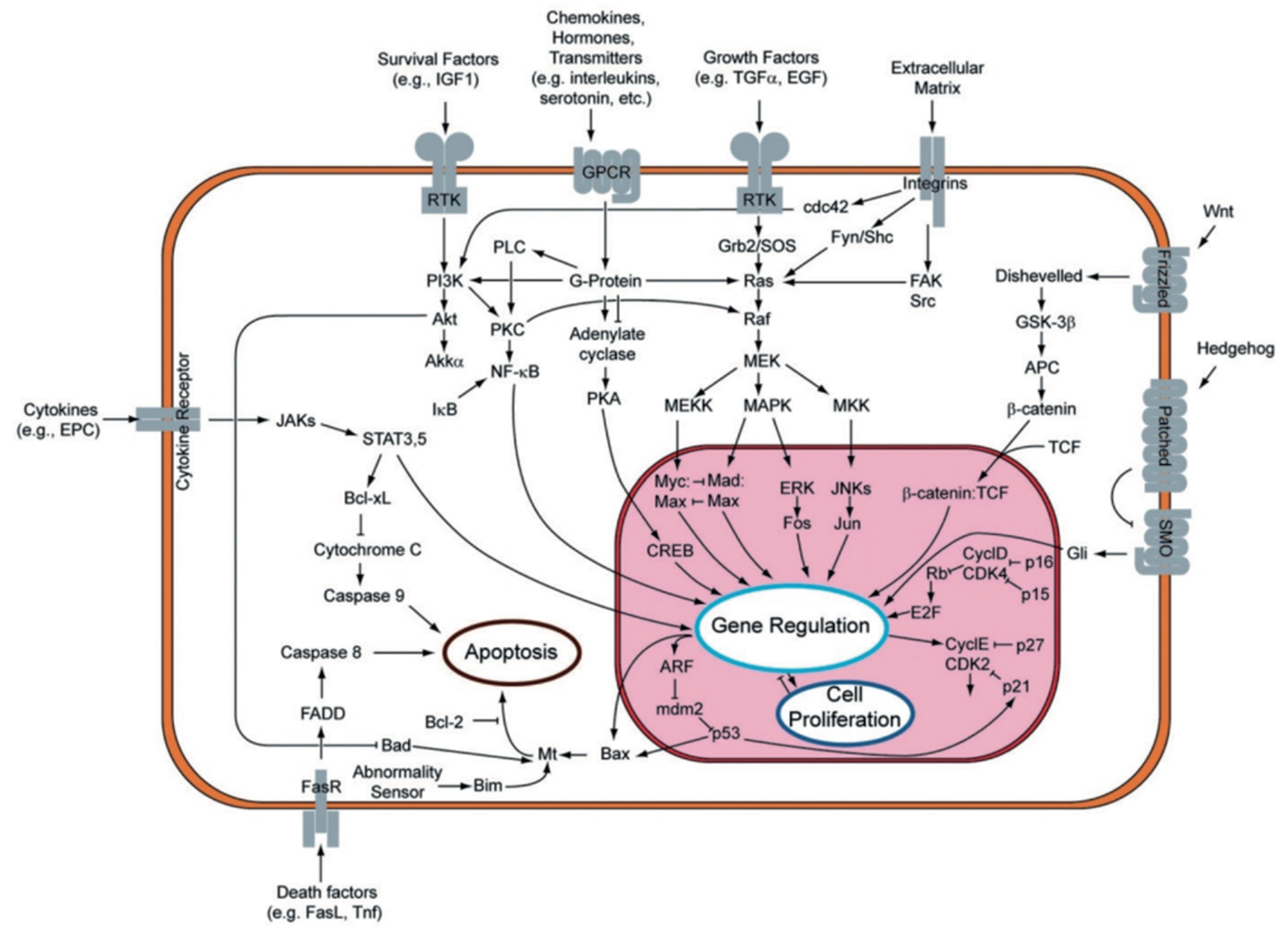

Figure 3. Signal transduction pathways.(26) (Adapted from Wikimedia Commons).

(e.g., rat aortic smooth muscle), c-Jun N-terminal Kinase (JNK) or ovarian tumor cell lines (28), and microglia (29). Thus, advance researches is needed focused on hormetic dose response quantitative features mechanisms, and how modifying dose could modulate it in a biological switching context.

\section{Hormesis and Biological Plasticity}

Phenotypic plasticity represents changes in an organism's observable properties such as behavior, morphology, and physiology, in response to the environment challenges. It is a fundamental adaptive feature, which has been extensively assessed within an ecological evolutionary framework. Phenotypic plasticity is the basic concept in biology, and applied in many broader subjects including evolutionary biology, genetics, ecology, neurosciences, developmental biology, stem cell biology and biogerontology, among others which concern about phenotypical adaptation to heterogeneous environments as described in Figure 5.(30-33)
In the principals, hormesis represents a central evolutionary strategy that is constrained by the limits of biological plasticity, where a high dose of stressors damaged a biological system, while a low dose of the same substance yield in a positive response in several physiologic functions from cell growth to cognition, thus hormesis can be seen as a component of biological plasticity. $(35,36)$ Hormesis dose response model is the quantitative features of plasticity. (34) Generally, the degree of phenotypic adaptive change and type of phenotypic alternative can vary depends on environmental conditions.(36) The phenotypic adjustments induced by hormesis could be long lasting, and probably irreversible. This adjustment might regards as a mechanism of survival in organism, and one potential mechanism involving transmission of chromatin modifications through mitosis (somatic memory) and meiosis (trans-generational memory.(37)

In many biomedical disciplines such as radiation biology, toxicology and environmental mutagenesis, the phenomenon of preconditioning and adaptive responses involving a low dose exposures of numerous agents (radiation, heavy metals, hepatotoxins such as carbon 


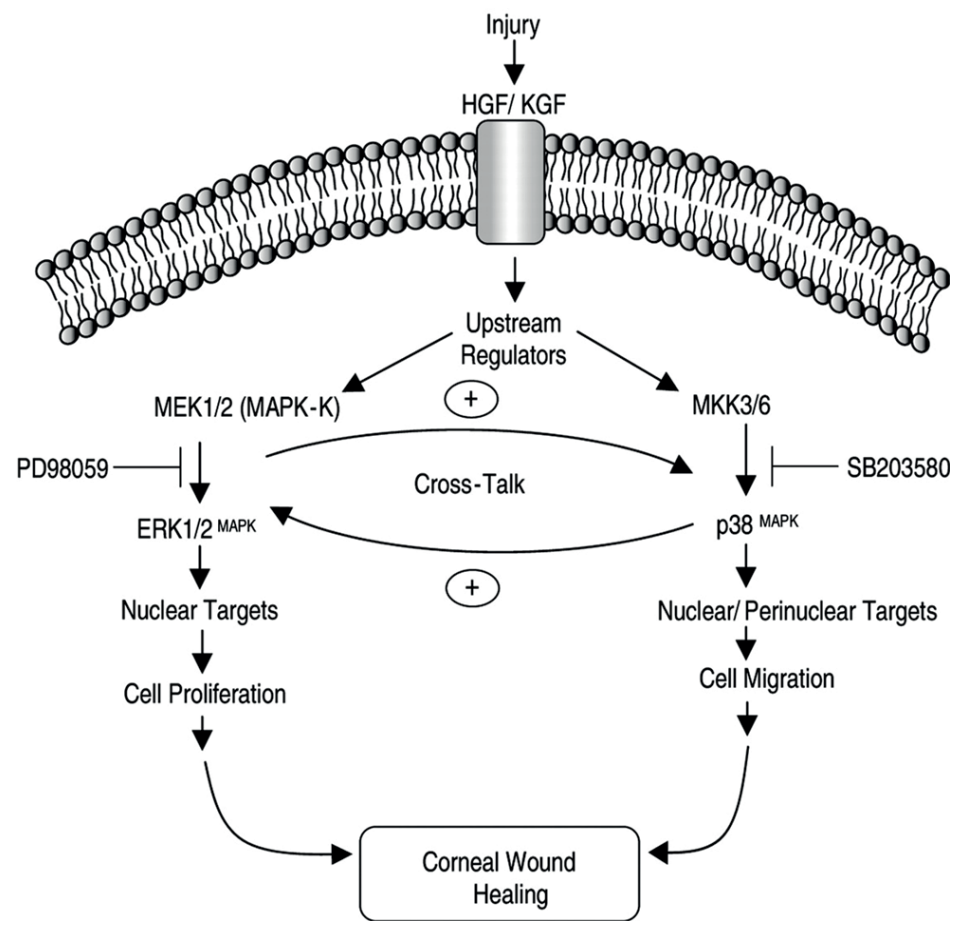

Figure 4. Schematic representation of activation of corneal epithelial wound healing by MAPK.(27) (Adapted with permission from American Society for Biochemistry and Molecular Biology). tetrachloride, numerous oxidants, hypoxia) and stressful procedures to protect against a subsequent and more massive exposure.(38) The prior exposure aims to produce an environmentally induced phenotype alteration with an enhanced adaptive response to the subsequent higher dose. Different magnitude of the pre-conditioning dose result in altered phenotype created. When the higher dose was exposed, and the phenotype response generally follows an inverted U-shaped dose response, that indicates that the change in plasticity is both qualitatively and quantitatively described by the hormetic dose response.

The point where the dose response crossed from stimulation to inhibition is called the Zero Equivalent Point
(ZEP) or threshold (Figure 1). The stimulatory response is believed to be at the below threshold dose, i.e.., when the organism acquired an altered/new adaptation phenotype. Then, the quantitative features in hormetic stimulatory zone represent a quantitative index of phenotypic plasticity, or a measure of biological performance, usually in average maximum response being about $30-60 \%$ greater than the control.(39,40) The models are remarkable consistent in different substances and endpoints, suggest a similar plasticity strategies and constraints are the rule throughout the biological sciences. Therefore, assessing the hormetic dose response could revealed the quantitative features of biology plasticity and clarify the basic biological concepts.

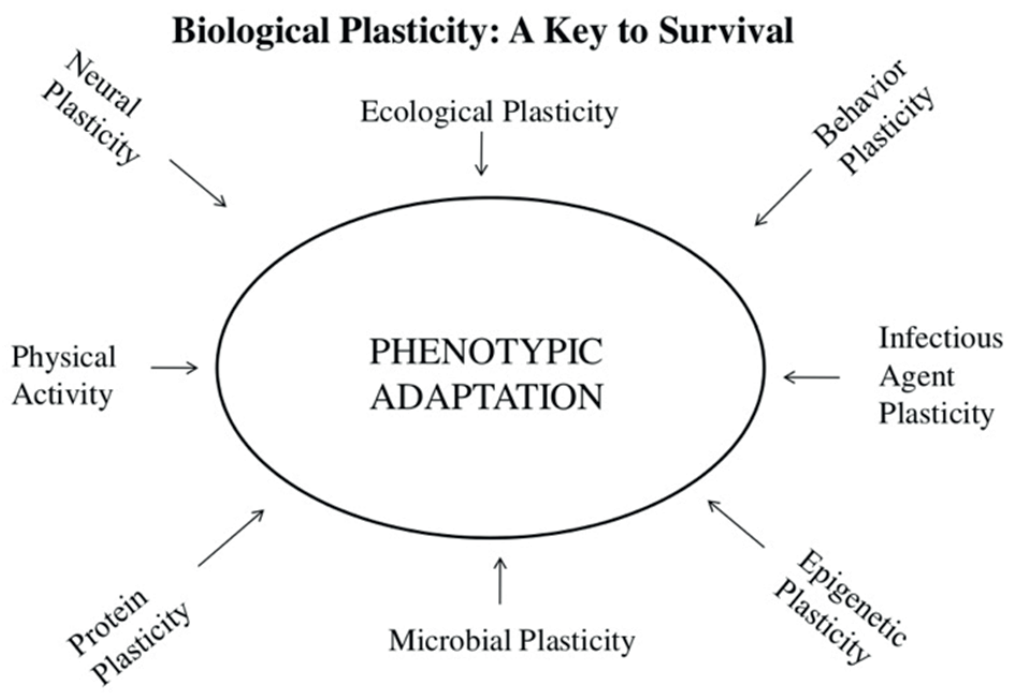

Figure 5. Biological plasticity: A key to survival.(34) (Adapted with permission from Springer Nature). 
(34) The hormesis-induced phenotypic responses do not manifest only at the molecular level but even substantial for life-history or demographic traits.(37)

One clear example is the macrophages polarization. Over the past two decades, studies recognize that macrophages can be reprogrammed toward pro-oxidative (called M1 macrophages) or anti-inflammatory forms (called M2 macrophages). A recent study hypothesized that macrophage reprogramming with polarization to M1 or M2 macrophage forms may be mediated via concentration gradients of signaling agents utilizing many substances, and that conforms to an hormetic dose response.(41)

Signaling Pathways: Mechanisms of Protection in Pre- and Post-conditioning

Preconditioning is an exposure of a sub-lethal physiologic stress to an organ, in order to confers subsequent protection from lethal injury by the prolonged exposure of same stressor. The term and concept of preconditioning later expanded rapidly with various modifiers for specific application such as ischemic preconditioning (IPC), hypoxic preconditioning and remote preconditioning. Hence, preconditioning concept developed into a different temporal exposure conditions where a low dose of stress administered in order to enhance repair and recovery processes after exposure of a more challenging stress, resulting in the term post-conditioning. $(38,42-44)$. Both pre- and post-conditioning phenomena were biphasic dose responses with quantitative features similar to hormesis. $(38,45)$ The adaptive phenomena as the specific manifestation to hormesis could present as an autoprotection, pre- and post-conditioning, and radiation- and chemical-induced adaptive responses.(46)

Hypoxia is one of the most frequently encountered stresses in health and disease. Previous studies demonstrated that hypoxia could be beneficial or harmful depend on the duration, frequency, and severity of hypoxic episodes. Obesity has been a growing problem worldwide, due to its cardiovascular morbidity and mortality. $(47,48)$ Metabolic Syndrome (MS), a group of metabolism abnormality including central obesity, hypertriglyceridemia, low levels of high-density lipoprotein (HDL) cholesterol, hypertension and hyperglycemia, is the most frequent clinical and metabolic consequence of obesity among others. $(49,50)$ Furthermore, overweight and obesity is the essential risk factor for obstructive sleep apnea (OSA). Indeed, twothirds of MS patients experience moderate to severe OSA, and the frequent association between OSA and obesity obscures the independent OSA contribution in metabolic and vascular dysfunction. $(51,52)$ OSA itself is recognized to be an independent risk factor for cardiovascular (53) and liver diseases (54). Intermittent hypoxia (IH) is the major component in OSA that is responsible to hepatic, glucose and lipid metabolism impairment, liver and vascular consequences of OSA.(54-57) In contrast, IH then proposed as a technique to improve physiological performance by utilizing the adaptation capability on ischemia-reperfusion preconditioning mechanisms, and shown to improve endothelial function in hypertension (58) and to limit infarct size (59). Thus, adaptation to IH could offer confer cardiovascular protection against more severe and sustained hypoxia, and other stresses such as ischemia. The results are different depend on the diversity and duration of reduced oxygen patterns applied, age, genotype variations, which determine the homeostatic response and decompensation. (60) The direct and cross benefit of IH was used as treatment and prevention of a variety of diseases, and to increase exercise training efficiency.

Hypoxia may affect nitric oxide (NO) production (Figure 6), NO tissue concentration, and nitric oxide synthases (NOS) expression by several mechanisms: (i) inadequate of $\mathrm{O}_{2}$ as NOS substrate, limit NO production; (ii) $\mathrm{O}_{2}$ act as NOS feedback inhibition; (iii) modulation of NO bioavailability; (iv) hypoxia inducible factor (HIF)-1 and other NOS transcription factors induced; (v) intracellular $\mathrm{Ca}^{2+}$ concentration and influx changed; (vi) NOS-regulating heat shock proteins (HSP) induced.(61) NO plays a pivotal role in adaptation to IH. It may be beneficial by increasing efficiency of vascular oxygen transport and energy supply $(62,63)$, inducing protective antioxidant enzymes such as catalase and superoxide dismutase (59), and HSP (60), stabilizing cellular membranes, and restricting apoptosis (61).

$\mathrm{NO}$ synthesis moderate stimulation and $\mathrm{NO}$ overproduction restriction, either directly or via NO negative feedback originating from NOS and alternative sources are the key of NO-dependent adaptation to IH. In adapted condition, NO synthesis and availability was enhanced despite of the oxygen lack, and this will induce the expression of other protective factors in robust and sustained way. Therefore, IH could represent an efficient and economic strategy to prevent and treat hypoxic or ischemic damage in organs and cells without drugs, with a similar protection resulted by physical training. In this respect strategic modulation of NO metabolism is of specific interest.(61) Some protocols were developed utilizing IH to improve cardio performance, induce neo-angiogenesis 


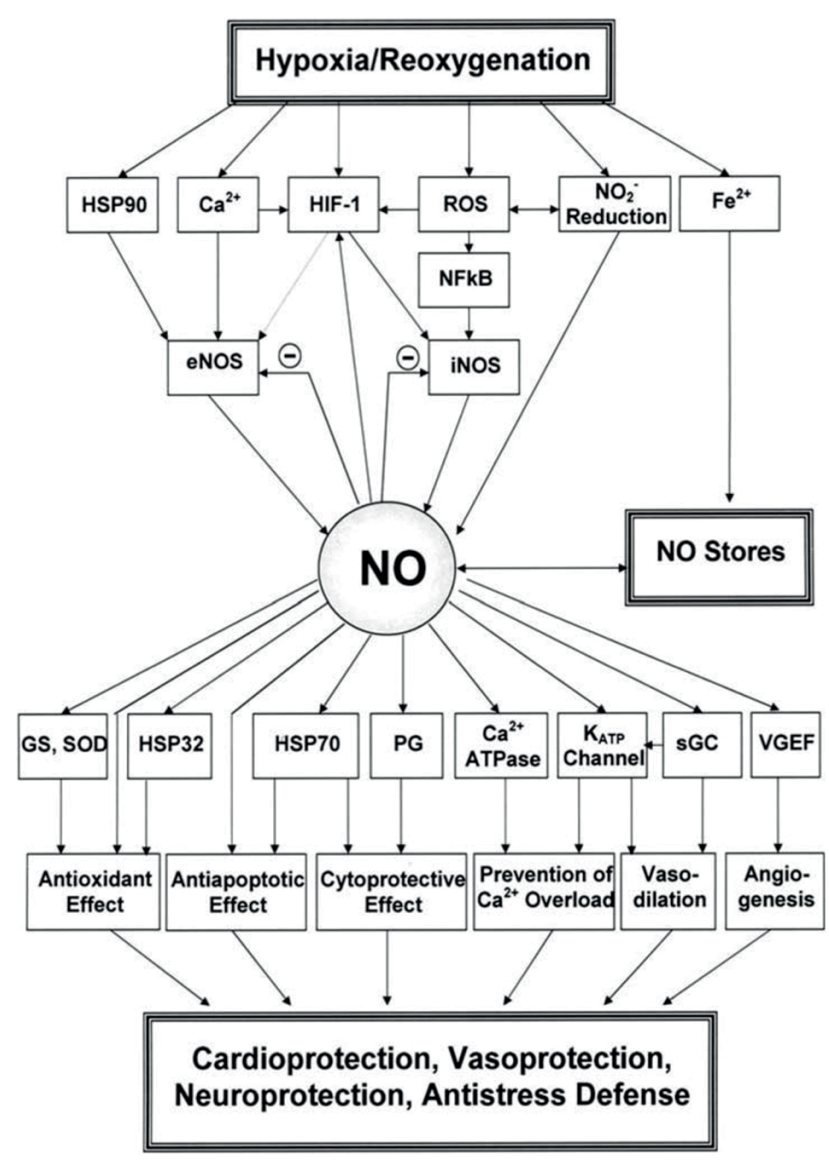

Figure 6. NO-dependent mechanisms in protective effects of adaptation to hypoxia.(60) (Adapted with permission from SAGE Publications).

and resist to ischemia-reperfusion injury, mediates by the phosphatidylinositol 3-kinase (PI3K)-Akt signaling. Such preconditioning maybe not reduce the incidence of myocardial ischemia-reperfusion injury, but at least reduce the myocardial damage severity. $(59,64)$

Ischemic conditioning performed by induced a transient, subcritical ischemia in a tissue to form endogenous protection. It is promising to protect ischemiasensitive organs such as the heart, the brain, and spinal cord. Both pre- and post-conditioning give a similar level of neuroprotection. The effects can appear immediately after the sublethal stress, or with a delay of days, termed as early or late effects. The early effects may associate to posttranslational modification of critical proteins (membrane receptors, mitochondrial respiratory chain), while the late effects come after gene up-or down- regulation. The transient ischemic attacks (TIA) could be relevant to brain ischemic preconditioning and may reduce the severity of subsequent strokes.(65)

Ischemic preconditioning (IPC) was first described in 1986, implemented as four 5 minutes cycles of coronary occlusion, which was insufficient to cause myocardial necrosis, and continue with a prolonged (40 minutes) coronary occlusion and reperfusion which caused infarction. This resulted in a substantial reduction (75\%) in the area of infarction in the subsequent exposure (66). The experiment in cerebral did in 4 years later using a brief ( 2 minutes) bilateral carotid occlusions, and could protect from neuronal death due to the subsequent 5 minutes bilateral carotid in gerbils.(67)

Ischemic pre- and postconditioning complex signaling pathways involve ligands released from ischemic myocardium, G-protein-linked receptors, membrane growth factor receptors, phospholipids, signaling kinases, NO, protein kinase C (PKC) and cGMP-dependent protein kinase or protein kinase $\mathrm{G}(\mathrm{PKG})$, mitochondrial ATP-sensitive potassium channels, reactive oxygen species (ROS), tumor necrosis factor (TNF- $\alpha$ and sphingosine1-phosphate. The mitochondrial permeability transition pore (mtPTP) is probably the final effector, together with the signal to prevent pore formation. Many studies tried to produce a roadmap of this signaling, hope to reveal a point to intervene and could patients with acute myocardial infarction whose hearts are being reperfused.(62)

Scientists acknowledged IPC as the most powerful cardioprotective intervention to salvage ischemic myocardium, reduce infarct size, and protect the cardiac. Acute myocardial infarction (AMI) is caused by a coronary thrombus, which could be dissolved with a thrombolytic agent. the size of a myocardial infarction is not only determined by ischemic damage, but also by reperfusion itself which contribute up to $50 \%$ of the final infarct size. Current standard of treatment is revascularization therapy (62), such as mechanical postconditioning using short periods of ischemia immediately after reperfusion. Oxygen re-introduction leads to sudden changes in myocardial viability, mediated by a burst of ROS produced in the mitochondria. This led to membrane damage, ion pumps interference, and volume dysregulation. Another hypothesis was the invasion of leucocyte to the reperfused tissue and attack viable myocytes by releasing free radicals.

Preconditioning and adaptive responses are the manifestation of hormesis. The constraints of biological plasticity may be an obstacle in enhancing the hormetic stimulation amplitude. However, in the resilient phenotype, the duration may be extended to resolve this. $(68,69)$ It is expected that efforts will be directed in these directions via metabolic engineering and other molecular approaches.(20) 


\section{Mitohormesis Promoting Health and Lifespan}

The levels of molecular damage increase over time, contributes to the biological process of aging, and organism's pathology and mortality. The precise mechanisms underlying aging process and how to control its rate to increase lifespan was investigated using models such as Saccharomyces cerevisiae, C. elegans, Drosophila melanogaster, and Mus musculus. From a molecular genetic perspective, hormetic adaptive and defensive dose response involving an alteration of genes' expression, and result in stress resistance. Utilizing the hormetic principal, longevity may be increased after achieving a greater resistance to a range of stressors. The treatments applied in many studies involving insulin/IGF-1 signaling pathway manipulations, dietary restriction (food intake significant reduction without malnutrition), oxygen reduction, physical activity, etc (Figure 7).(70) The hormetic dose response has important implications for the fields of hazard assessment, risk assessment for carcinogens, endocrine disruption, for pharmaceuticals/natural products that enhance biological performance, and pre/post conditioning activities that upregulate adaptive mechanisms, enhancing resilience.

A brief thermal stress exposure is sufficient to induce thermotolerance in C. Elegans and cause small, but statistically significant increases in life span.(71) Apparently, the dose-response relationships for thermotolerance and longevity are very similar (68); after subjected to a mild heat stress, the expression levels of the small heat-shock protein gene hsp-16 in C. Elegans are predictive of both thermotolerance and life span.(72) Another study suggested an extension of lifespan in $C$. Elegans after glucose restriction, which induces hormesis via mitochondrial respiration and oxidative stress enhancement. $(73,74)$ Seems that increased stress resistance will increased life span.(1)

ROS regards as toxic oxygen-containing molecules that induce molecular damage in the cell, and contribute to aging. $(75,76)$ In contrary, mildly elevated ROS alter physiologic rates (77-79) and contribute to longevity in some organisms including clk-1 worms (79-81). Treatment with the superoxide-generator paraquat induce oxidative damage $(77,80,82)$ and decreased the levels of protein carbonylation $(83,84)$, decreased lipofuscin accumulation (85), and decreased 4-Hydroxynonenal (4-HNE) $(86,87)$, while increasing the levels of F3-isoprostanes (88) in the worms. Measurement of ROS level in clk-1 worms using redox dyes showed increased level of ROS in whole worm extracts and in the heads of whole worms (82), but not in isolated mitochondria (80). This indicate that the worms have increased levels of ROS but decreased levels of at least some types of oxidative damage.

Oxidative damage is a result of the homeostasis between ROS production, ROS detoxification and repair, thus the result suggested that antioxidant defense or damage repair may be increased in the worms. The elevated ROS in clk-1 worms upregulates multiple classes of antioxidant genes during adulthood, increased the level of catalase activity (89), while the increasing of superoxide dismutase (SOD) protein or mRNA showed different results $(83,90$ -

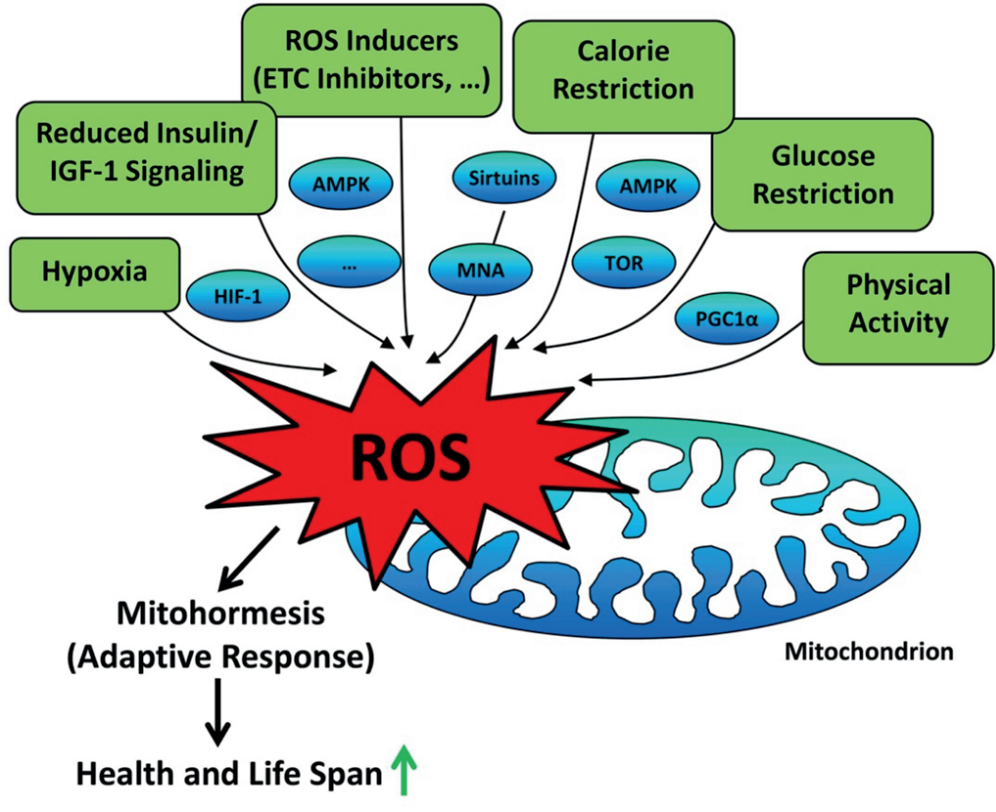

Figure 7. A non-exhaustive overview on lifespan-extending interventions linked to mitohormetic ROS signalling.(70) (Adapted with permission from SAGE Publication). 
92). Increased levels of ROS in the mitochondria further increase clk-1 lifespan, while cytoplasmic ROS decrease it, but actually the specific compartment does not affect on lifespan. What counted to the longevity of clk-1 worms is both ROS-dependent and ROS-independent mechanisms on stress resistance.(93)

Besides their responsibility in conversing the bulk of nutritive energy, mitochondria play an important role in aging processes and the related diseases. Over $90 \%$ of all intracellular ROS was produced as the inevitable by-product of mitochondria oxidative phosphorylation (OxPhos) process, with conversion of $0.15-5 \%$ of total oxygen consumed by resting cells (89-92). Thus, mitochondria are the main producers of energy and ROS within the cell, which majorly impact on cell's physiological and pathophysiological processes. Mitochondrial dysfunction increased oxidative stress and associated with many diseases such as diabetes, cancer and neurodegenerative disorders, including Alzheimer's and Parkinson's disease (94-97), and of course aging (97-99), whereas the role of ROS in this regard is still unclear. Hence, ROS in different levels may exert opposite effects on biological outcomes. At a high dose, ROS clearly induce detrimental effects on cellular integrity, while in low amounts ROS may exert specific functions in promoting general health, and specifically lifespan. By today, a range of stressors provide hormetic effects on aging process $(10,11,18,100-102)$. The term of mitochondrial hormesis or mitohormesis later specified in 2006 (103), which used in setting for mitochondrial ROS (mtROS) as sublethal stressors promoting lifespan in a lower doses (73). Figure 8 showed how ROS transcriptionally influence stress resistance and lifespan.

Calorie restriction (CR) has been applied in study for aging since world war II, refers to dietary regimens that reduce $10-50 \%$ calorie intake without incurring malnutrition (104). CR induces metabolic adaptation and reduces regenerative diseases including cardiovascular diseases, cancer, and type 2 diabetes mellitus (T2DM) (105109) as well as the factors involved in the before-mentioned diseases (110-112). CR is capable of inducing stress defense mechanisms which reflect mitohormetic responses, notably in ROS detoxification, involving radical-scavenging enzymes and phase I and II biotransformation response enzymes. $(73,74,81,113-125)$

Mitohormetic mechanism was showed in $\mathrm{CR}$ as hypothesized in some independent observations. Initial induction of $\mathrm{mtROS}$ by $\mathrm{CR}$ induces stress defense mechanisms and culminate in secondarily decreased of mtROS levels, in a time-resolved manner.(81) Some misinterpretation happened to the subsequent decrease in ROS as being the primary result of CR, whereas it is an adaptive detoxifying mechanism, and $\mathrm{CR}$ is the essential trigger of mitohormetic mechanisms. $(73,126)$

Thioredoxin is another important factor regarding the effects of CR. It extends C. elegans lifespan under dietary deprivation and knockouts of eat-2, a genetic surrogate of nematodal CR.(127) The oxidoreductase thioredoxin roles in antioxidant response via Nrf2 binding at the antioxidants responsive elements (AREs), redox regulation, acts as electron donor for metabolic enzymes, and prevents aggregation of cytosolic proteins in the cell. $(128,129) \mathrm{Nrf} 2$ transcription factor activation from the leucine zipper family is indeed a crucial pathway to mediate mitohormesis. Nrf2 in a normal condition is insulated by its specific repressor Kelch-like ECH-Associated Protein 1 (KEAP1) in the cytoplasm. KEAP1 is an actin-binding protein, which also targets Nrf2 for proteasomal degradation.(130) The redoxsensitive cysteine residues in KEAP-1 sensors oxidants and electrophiles, leading to abrogation of the Nrf2/KEAP1

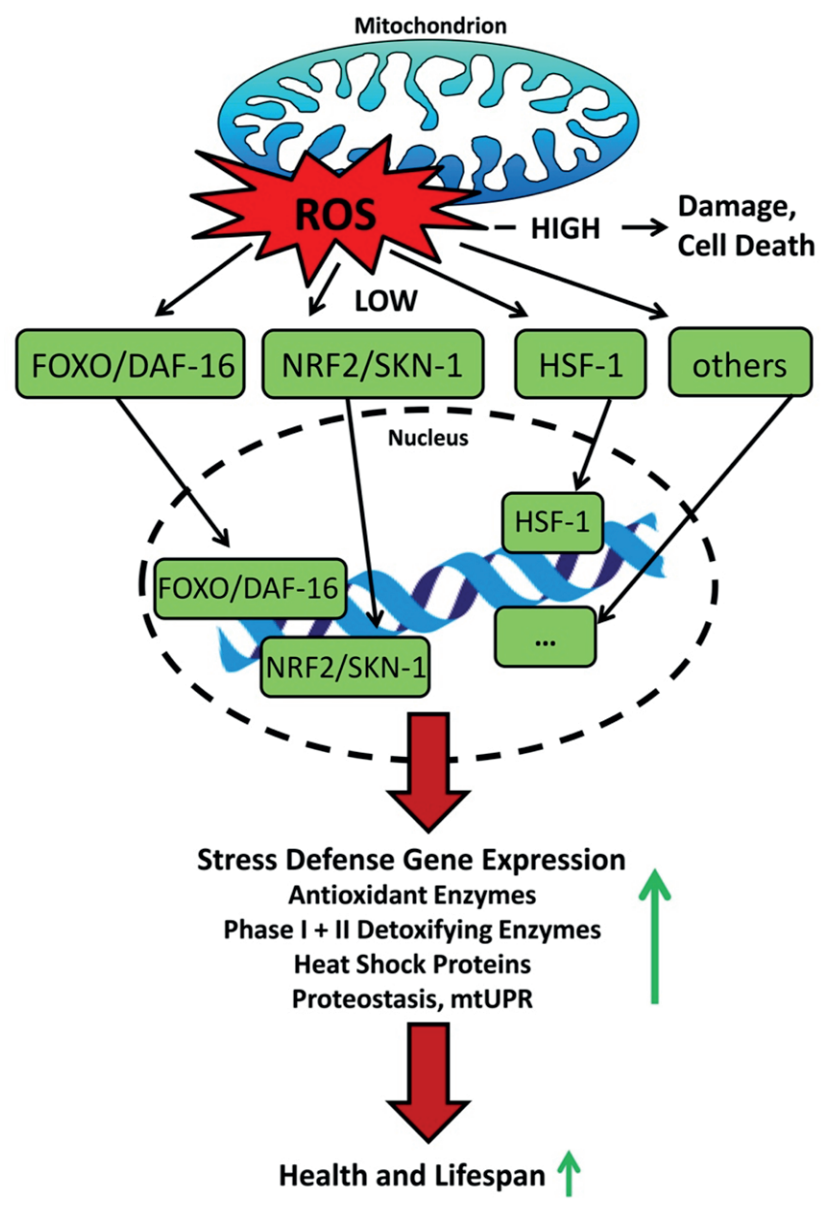

Figure 8. Overview on how ROS transcriptionally influence stress resistance and lifespan.(70) (Adapted with permission from SAGE Publication). 
complex.(130,131) Nrf2 is shown to be activated by ROS $(131,132)$, and binds to the DNA via AREs to coordinate the stress response by boosting the expression of antioxidant proteins, and phase I and II detoxification enzymes.(133)

Due to various interventions mechanisms, there are some other transcription factors which are important for lifespan extension including member of the Forkhead transcription factors (FOX) and heat shock factor 1 (HSF-1). FOXOs activate a number of target genes involved in cellular stress response. Oxidative stress induce mitohormesis and upregulates superoxide dismutase and catalase in FOXOdependent pathway (134-136), while stress-response induced by CR is mediated by FOXAs $(137,138)$. Overall, a number of important lifespan-regulating molecular pathways were unified in mitohormesis, and prospectively to become a common denominator in aging research.(70)

\section{Dietary Factors, Hormesis and Health}

Many studies demonstrated different dietary factors effect on health and longevity. Some of those showed incontrovertible evidences, while some other were inconclusive. Beyond of the food variety, the amount of calories consumed firmly showed an associated with the risk of many prominent age-related diseases.(139-141) Higher calories increase the risks of such metabolic and even neurodegenerative disorders. Regarding the dietary components, diet high in saturated fats, cholesterol and trans-fats may promote agerelated disease $(142,143)$, while simple sugars increase the risk of diabetes (144). Healthy diets recommendation including lots of vegetables and fruits (145), fish (146) and nuts (147).

Oxidative stress is often be blamed for ageing process and mortality. Therefore, modifying dietary factors might influence disease processes and longevity. Dietary energy restriction (DER), and substances contain in vegetables, fruits, nuts and fish oils exert anti-oxidative effects.(148) Animal and in vitro studies found that dietary factor induced specific adaptive stress response signaling pathways, i.e., hormesis.(149) Another highly controlled studies on animals showed that DER either by controlled CR or intermittent fasting can increased animal cells to various types of stress. DER studies in human also resulted in counteract disease processes. Alternate day fasting reduced inflammation markers and oxidative stress and also improve symptoms in asthma subjects.(150)

DER regiment in animals change several biochemical and molecular which are consistent with the involvement of hormesis mechanisms, propose the beneficial effects of DER for health. HSP level was increase in several different tissues, which serve a chaperone function that protects proteins against damage. For example, HSP-70 levels are increased in liver cells of rats treated on CR (151), while intermittent fasting increased HSP-70 and glucose-regulated protein 78 in rat's brain synapses (152).

Another cytoprotective benefit of DER is the upregulation of antioxidants. Diabetic rodents demonstrated increased levels of some antioxidant enzymes in their liver after DER maintenance (153), and reduced calorie diet result in increased vitamin E and coenzyme Q10, also higher plasma membrane redox enzyme activities, in brain cell membranes compared to control rats fed ad libitum (154). The increased antioxidant levels are consistent with reduced oxidative damage to proteins, lipids and DNA in various tissues of animals as a result of hormetic mechanisms on DER (155), which involve system adaptation on cellular energy regulation. For example, some proteins which involved in mitochondrial oxidative phosphorylation (138), glycolysis (148) and nicotinamide adenine dinucleotide (NAD)/NADH metabolism (166) regulation were upregulated in some cell types as respond to DER.

The current evidences for hormetic response due to environmental toxins in biological systems raise the possibility that the same mechanism also occurs by the induction from chemicals in foodstuffs (particularly plants), resulting from chemicals ingestion in doses within the hormetic range. Plants developed biosynthetic pathways and generate more than 100 biotoxins in its evolution in order to prevent microorganisms and insects from eating them.(164) The harmful chemicals usually concentrated in exposed vulnerable regions of the plant such as the skin of fruits and the growing buds. The phytochemicals can be toxic to mammalian cells in high concentrations, but in subtoxic doses, it may induce adaptive stress responses. Several studies performed on the hormetic actions of specific phytochemicals, such as high levels of isothocyanates in broccoli which induced the expression of cytoprotective phase 2 proteins in liver, intestinal and stomach cells (167); curcumin contains in curry spices induce adaptive stress responses genes and protect cells in animal models of cataract formation, pulmonary toxicity, multiple sclerosis and Alzheimer's disease (168); resveratrol found in grape skin protect cells in models of myocardial infarction and stroke (169). Nrf-2 is involved in the hormetic signal transduction, by its binding to ARE upstream of genes and encodes cytoprotective antioxidant enzymes and phase-2 proteins.(170) Other pathways such in resveratrol, involving 
Table 1. Summarized agents that induce hormesis-related to dietary and health.

\begin{tabular}{|c|c|c|c|}
\hline Hormetin Agents & Food in Diet & Stress Pathway & Effect \\
\hline $\begin{array}{l}\text { Phytochemicals } \\
\text { (isothocyanates, curcumin) }\end{array}$ & Broccoli, curry spices & $\begin{array}{l}\text { Activation of nuclear factor } \\
\text { erythroid } 2 \text { (Nrf2) }\end{array}$ & $\begin{array}{l}\text { Broccoli induced the expression of } \\
\text { cytoprotective phase } 2 \text { proteins in liver, } \\
\text { intestinal and stomach cells. Curcumin } \\
\text { protects against cataract formation, pulmonary } \\
\text { toxicity, multiple sclerosis and Alzheimer's } \\
\text { disease. }\end{array}$ \\
\hline Resveratrol & Grapes skin, red wine & $\begin{array}{l}\text { Regulation of redox } \\
\text { homeostasis, Activation of } \\
\text { Nrf2 and sirtuin pathway, } \\
\text { Blocking of nuclear factor } \mathrm{\kappa B} \\
\text { (NF- } \mathrm{\kappa B} \text { ) }\end{array}$ & $\begin{array}{l}\text { Resveratrol protect cells in models of } \\
\text { myocardial infarction and stroke. }\end{array}$ \\
\hline Alcohol & Alcoholic drinks & $\begin{array}{l}\text { Alterations in protein kinase } \mathrm{C} \\
\text { (PKC) }\end{array}$ & $\begin{array}{l}\text { Moderate consumption of alcohol increase in } \\
\text { HDL cholesterol, increased insulin sensitivity, } \\
\text { anti-inflammatory effect, increase adiponectin, } \\
\text { increase fibrinolysis, decrease in platelet } \\
\text { aggregation, and coagulation and improved } \\
\text { endothelial function. }\end{array}$ \\
\hline
\end{tabular}

activation of sirtuin - FOXO, and increase the expression of antioxidant enzymes, and cell survival-promoting proteins. (162) Some other phytochemicals may activate the hormetic transcription factors NF- $\mathrm{KB}$ and $\mathrm{CREB}$ and induce genes encoding growth factors and anti- apoptotic proteins. $(163,164)$

Since the early recorded history, alcohol has been an integral part of human culture. Moderate alcohol consumption associated with beneficial health effects, but excess and binge drinking leads to increasing risk of cardiovascular diseases and mortlity.(165-170) Thus, moderate amount of alcohol is protective against coronary artery disease (CAD), and the higher amount exert different effect.(171) Multiple studies observed a J- or U-shaped association between alcohol consumption and all-cause mortality.(169-175) The benefit of moderate alcohol consumption include an increase in HDL cholesterol, increased insulin sensitivity, favorable effects mediated by alterations in PKC, anti-inflammatory effect, increase adiponectin, increase fibrinolysis, decrease in platelet aggregation, and coagulation and improved endothelial function.(176-178) The complex metabolic pathways are interconnected on these mechanisms. The role of individual factors are not yet be elucidated, but some studies on the biphasic dose responses associated with increased expression of genes encoding cytoprotective proteins including antioxidant enzymes, protein chaperones, growth factors and mitochondrial proteins. Table 1 showed some summarized agents that induce hormesis-related to dietary and health. More research on how dietary factors exert dose response and kinetic characteristics in animals and humans will lead to a better understanding of hormesis and to improvements in dietary interventions for disease prevention and treatment.(149)

\section{Conclusion}

Human bodies are highly adaptive. Exposure to a stressor in adequate dose evidently can induce stress responses that are protective against the same stress exposure in higher levels. While constant high-level exposure induce tolerance to avoid overstressing the system. Our body needs to adjust to different functions from fecundity versus longevity until energy conservation versus expenditure. These adaptations are essential to protect us from unpredictable environmental changes. Our endocrine, nervous, and immune systems are capable to adapt, since these systems directly sense the environmental changes and communicate the perceived change to the rest of the body. A lot of adaptation occurred during evolution and the training formed the body that is more resistant to stress.

\section{References}

1. Gems D, Partridge L. Stress-response hormesis and aging: "That which does not kill us makes us stronger." Cell Metab. 2008; 7: 200-3.

2. Li X, Yang T, Sun Z. Hormesis in health and chronic diseases. Trends Endocrinol Metab. 2019; 30: 944-58.

3. Omiecinski CJ, Vanden Heuvel JP, Perdew GH, Peters JM. Xenobiotic metabolism, disposition, and regulation by receptors: from biochemical phenomenon to predictors of major toxicities. Toxicol Sci Off J Soc Toxicol. 2011; 120 (Suppl 1): S49-75.

4. Russell WL. The effect of radiation dose rate and fractionation on mutation in mice. In: Sobels FH, editor. Repair from Genetic Radiation Damage and Differential Radiosensitivity in Germ Cells. Proceedings of an International Symposium. Leiden: University of Leiden; 1963. p. 205-17.

5. Russell WL. Environmental effects of producing electric power, 
Joint Committee on Atomic Energy, 91st Congress of the United States, Washington, DC, USA, October and November 1969. In: Summary of the Effect of Dose Rate on the Induction of Mutations by Radiation in the Mouse. Washington, DC: USA Government Printing Office; 1969. p.1108.

6. Russell WL, Russell LB, Kelly EM. Radiation dose rate and mutation frequency. Science. 1958; 128: 1546-50.

7. Calabrese EJ. Hormesis and medicine. Br J Clin Pharmacol. 2008; 66: 594-617.

8. Calabrese EJ. Converging concepts: adaptive response, preconditioning, and the Yerkes-Dodson Law are manifestations of hormesis. Ageing Res Rev. 2008; 7: 8-20.

9. Southam C, Ehrlich J. Effects of extracts of western redcedar heartwood on certain wood-decaying fungi in culture. Phytopathology. 1943; 33: 517-24.

10. Calabrese EJ, Baldwin LA. Defining hormesis. Hum Exp Toxicol. 2002; 21: 91-7.

11. Cypser JR, Johnson TE. Multiple stressors in Caenorhabditis elegans induce stress hormesis and extended longevity. J Gerontol Ser A. 2002; 57: B109-14.

12. Luckey TD. Hormesis with Ionizing Radiation. Boca Raton: CRC Press; 2019.

13. Luckey TD. Radiation Hormesis. Boca Raton: CRC Press; 1991.

14. Calabrese EJ, Baldwin LA. Hormesis: a generalizable and unifying hypothesis. Crit Rev Toxicol. 2001; 31: 353-424.

15. Pickrell JA, Oehme FW. Invited response to definition of hormesis. Hum Exp Toxicol. 2002; 21: 107-9.

16. Feynman RP, Robbins JW. The Pleasure of Finding Things Out: the Best Short Works of Richard P. Feynman. New York: Basic Books; 2005.

17. Calabrese EJ. Hormesis: why it is important to toxicology and toxicologists. Environ Toxicol Chem. 2008; 27: 1451-74.

18. Mattson MP. Hormesis defined. Ageing Res Rev. 2008; 7: 1-7.

19. Calabrese EJ. Hormetic mechanisms. Crit Rev Toxicol. 2013; 43: 580-606.

20. Calabrese EJ, Mattson MP. How does hormesis impact biology, toxicology, and medicine? Npj Aging Mech Dis. 2017; 3: 13. doi: 10.1038/s41514-017-0013-z.

21. Szabadi E. A model of two functionally antagonistic receptor populations activated by the same agonist. J Theor Biol. 1977; 69: 101-12.

22. Accomazzo MR, Cattaneo S, Nicosia S, Rovati GE. Bell-shaped curves for prostaglandin-induced modulation of adenylate cyclase: two mutually opposing effects. Eur J Pharmacol. 2002; 454: 107-14.

23. Alfonzo MJ, de Becemberg IL, de Villaroel SS, de Herrera VN, Misle AJ, de Alfonzo RG. Two opposite signal transducing mechanisms regulate a G-protein-coupled guanylyl cyclase. Arch Biochem Biophys. 1998; 350: 19-25.

24. Järv J. A model of non-exclusive binding of agonist and antagonist on G-protein coupled receptors. J Theor Biol. 1995; 175: 577-82.

25. Järv J, Hautala R, Åkerman KEO. Dual effect of muscarinic receptor agonists on $\mathrm{Ca} 2+$ mobilization in SH-SY5Y neuroblastoma cells. Eur J Pharmacol Mol Pharmacol. 1995; 291: 43-50.

26. Wikimedia Commons [Internet]. File: Signal transduction pathways. svg [cited Mar 23, 2020]. Available from: https://commons. wikimedia.org/wiki/File:Signal_transduction_pathways.svg.

27. Sharma GD, He J, Bazan HEP. p38 and ERK1/2 Coordinate cellular migration and proliferation in epithelial wound healing evidence of cross-talk activation between MAP kinase cascades. J Biol Chem. 2003; 278: 21989-97.

28. Cheung LWT, Leung PCK, Wong AST. Gonadotropin-releasing hormone promotes ovarian cancer cell invasiveness through
c-Jun NH2-terminal kinase-mediated activation of matrix metalloproteinase (MMP)-2 and MMP-9. Cancer Res. 2006; 66: 10902-10.

29. Bianchi R, Kastrisianaki E, Giambanco I, Donato R. S100B protein stimulates microglia migration via RAGE-dependent up-regulation of chemokine expression and release. J Biol Chem. 2011; 286: 7214-26.

30. Simons AM, Wagner I. The characterization of complex continuous norms of reaction. Oikos. 2007; 116: 986-94.

31. Huey RB, Kingsolver JG. Evolution of thermal sensitivity of ectotherm performance. Trends Ecol Evol. 1989; 4: 131-5.

32. Izem R, Kingsolver JG. Variation in continuous reaction norms: quantifying directions of biological interest. Am Nat. 2005; 166: 277-89.

33. de Jong G. Phenotypic plasticity as a product of selection in a variable environment. Am Nat. 1995; 145: 493-512.

34. Calabrese EJ, Mattson MP. Hormesis provides a generalized quantitative estimate of biological plasticity. J Cell Commun Signal. 2011; 5: 25-38.

35. Puzzo D, Privitera L, Palmeri A. Hormetic effect of amyloid-beta peptide in synaptic plasticity and memory. Neurobiol Aging. 2012; 33: 1484.e15-1484.e24.

36. Via S, Gomulkiewicz R, De Jong G, Scheiner SM, Schlichting CD, Van Tienderen PH. Adaptive phenotypic plasticity: consensus and controversy. Trends Ecol Evol. 1995; 10: 212-7.

37. CostantiniD. Hormesis promotesevolutionary change.Dose-Response. 2019; 17: 1559325819843376. doi: 10.1177/1559325819843376.

38. Calabrese EJ, Bachmann KA, Bailer AJ, Bolger PM, Borak J, Cai $\mathrm{L}$, et al. Biological stress response terminology: Integrating the concepts of adaptive response and preconditioning stress within a hormetic dose-response framework. Toxicol Appl Pharmacol. 2007; 222: $122-8$.

39. Calabrese EJ, Blain R. The occurrence of hormetic dose responses in the toxicological literature, the hormesis database: an overview. Toxicol Appl Pharmacol. 2005; 202: 289-301.

40. Calabrese EJ, Blain RB. Hormesis and plant biology. Environ Pollut Barking Essex 1987. 2009; 157: 42-8.

41. Calabrese EJ. Hormesis: Path and progression to significance. Int $\mathrm{J}$ Mol Sci. 2018; 19: 2871. doi: 10.3390/ijms19102871.

42. Zhao ZQ, Corvera JS, Halkos ME, Kerendi F, Wang NP, Guyton RA, et al. Inhibition of myocardial injury by ischemic postconditioning during reperfusion: comparison with ischemic preconditioning. Am J Physiol Heart Circ Physiol. 2003; 285: H579-88.

43. Hausenloy DJ. Cardioprotection techniques: preconditioning, postconditioning and remote conditioning (basic science). Curr Pharm Des. 2013; 19: 4544-63.

44. Hausenloy DJ, Yellon DM. The therapeutic potential of ischemic conditioning: an update. Nat Rev Cardiol. 2011; 8: 619-29.

45. Ito T, Sawauchi K. Inhibitory effects on cadmium-induced testicular damage by pretreatment with smaller cadmium dose. Okajimas Folia Anat Jpn. 1966; 42: 107-17.

46. Calabrese EJ. Preconditioning is hormesis part I: Documentation, dose-response features and mechanistic foundations. Pharmacol Res. 2016; 110: 242-64.

47. Allende-Vigo MZ. Pathophysiologic mechanisms linking adipose tissue and cardiometabolic risk. Endocr Pract Off J Am Coll Endocrinol Am Assoc Clin Endocrinol. 2010; 16: 692-8.

48. Kopelman PG. Obesity as a medical problem. Nature. 2000; 404: 635-43.

49. Thakur ML, Sharma S, Kumar A, Bhatt SP, Luthra K, Guleria R, et al. Nonalcoholic fatty liver disease is associated with subclinical atherosclerosis independent of obesity and metabolic syndrome in 
Asian Indians. Atherosclerosis. 2012; 223: 507-11.

50. Villanova N, Moscatiello S, Ramilli S, Bugianesi E, Magalotti D, Vanni E, et al. Endothelial dysfunction and cardiovascular risk profile in nonalcoholic fatty liver disease. Hepatol Baltim Md. 2005; 42: 473-80.

51. Drager LF, Lopes HF, Maki-Nunes C, Trombetta IC, Toschi-Dias E, Alves MJNN, et al. The impact of obstructive sleep apnea on metabolic and inflammatory markers in consecutive patients with metabolic syndrome. PloS One. 2010; 5: e12065. doi: 10.1371/ journal.pone. 0012065 .

52. Trzepizur W, Gaceb A, Arnaud C, Ribuot C, Levy P, Martinez MC, et $a l$. Vascular and hepatic impact of short-term intermittent hypoxia in a mouse model of metabolic syndrome. PLOS ONE. 2015; 10 : e0124637. doi: 10.1371/journal.pone.0124637.

53. Marin JM, Carrizo SJ, Vicente E, Agusti AGN. Long-term cardiovascular outcomes in men with obstructive sleep apnoeahypopnoea with or without treatment with continuous positive airway pressure: an observational study. Lancet Lond Engl. 2005; 365: 1046-53.

54. Minville C, Hilleret MN, Tamisier R, Aron-Wisnewsky J, Clement K, Trocme $\mathrm{C}$, et al. Nonalcoholic fatty liver disease, nocturnal hypoxia, and endothelial function in patients with sleep apnea. Chest. 2014; 145: 525-33.

55. Priou P, Le Vaillant M, Meslier N, Chollet S, Masson P, Humeau $\mathrm{MP}$, et al. Independent association between obstructive sleep apnea severity and glycated hemoglobin in adults without diabetes. Diabetes Care. 2012; 35: 1902-6.

56. Trzepizur W, Le Vaillant M, Meslier N, Pigeanne T, Masson P, Humeau MP, et al. Independent association between nocturnal intermittent hypoxemia and metabolic dyslipidemia. Chest. 2013; 143: 1584-9.

57. Punjabi NM, Caffo BS, Goodwin JL, Gottlieb DJ, Newman AB, O'Connor GT, et al. Sleep-disordered breathing and mortality: a prospective cohort study. PLoS Med. 2009; 6: e1000132. doi: 10.1371/journal.pmed.1000132.

58. Manukhina EB, Jasti D, Vanin AF, Downey HF. Intermittent hypoxia conditioning prevents endothelial dysfunction and improves nitric oxide storage in spontaneously hypertensive rats. Exp Biol Med Maywood NJ. 2011; 236: 867-73.

59. Milano G, Abruzzo PM, Bolotta A, Marini M, Terraneo L, Ravara $\mathrm{B}$, et al. Impact of the phosphatidylinositide 3-kinase signaling pathway on the cardioprotection induced by intermittent hypoxia. PLoS ONE. 2013; 8: e76659. doi: 10.1371/journal.pone.0076659.

60. Almendros I, Wang Y, Gozal D. The polymorphic and contradictory aspects of intermittent hypoxia. Am J Physiol Lung Cell Mol Physiol. 2014; 307: L129-40.

61. Manukhina EB, Downey HF, Mallet RT. Role of nitric oxide in cardiovascular adaptation to intermittent hypoxia. Exp Biol Med. 2006; 231: 343-65.

62. Meerson FZ, Pshennikova MG, Malyshev IY. Adaptive defense of the organism. Ann NY Acad Sci. 1996; 793: 371-85.

63. Serebrovskaya TV. Intermittent hypoxia research in the former soviet union and the commonwealth of independent States: history and review of the concept and selected applications. High Alt Med Biol. 2002; 3: 205-21.

64. Calabrese EJ. Preconditioning is hormesis part II: How the conditioning dose mediates protection: Dose optimization within temporal and mechanistic frameworks. Pharmacol Res. 2016; 110: 265-75.

65. Dezfulian C, Garrett M, Gonzalez NR. Clinical application of preconditioning and postconditioning to achieve neuroprotection. Transl Stroke Res. 2013; 4: 19-24.
66. Murry CE, Jennings RB, Reimer KA. Preconditioning with ischemia: a delay of lethal cell injury in ischemic myocardium. Circulation. 1986; 74: 1124-36.

67. Kitagawa K, Matsumoto M, Tagaya M, Hata R, Ueda H, Niinobe M, et al. "Ischemic tolerance" phenomenon found in the brain. Brain Res. 1990; 528: 21-4.

68. Gidday JM. Extending injury- and disease-resistant CNS phenotypes by repetitive epigenetic conditioning. Front Neurol. 2015; 6: 42. doi: 10.3389/fneur.2015.00042.

69. Kishimoto S, Uno M, Okabe E, Nono M, Nishida E. Environmental stresses induce transgenerationally inheritable survival advantages via germline-to-soma communication in Caenorhabditis elegans. Nat Commun. 2017; 8: 14031. doi: 10.1038/ncomms14031.

70. Ristow M, Schmeisser K. Mitohormesis: promoting health and lifespan by increased levels of reactive oxygen species (ROS). Dose Response. 2014; 12: 288-341.

71. Lithgow GJ, White TM, Melov S, Johnson TE. Thermotolerance and extended life-span conferred by single-gene mutations and induced by thermal stress. Proc Natl Acad Sci USA. 1995; 92: 7540-4.

72. $\mathrm{Wu} \mathrm{D}$, Rea SL, Yashin AI, Johnson TE. Visualizing hidden heterogeneity in isogenic populations of C. elegans. Exp Gerontol. 2006; 41: 261-70.

73. Schulz TJ, Zarse K, Voigt A, Urban N, Birringer M, Ristow M. Glucose restriction extends Caenorhabditis elegans life span by inducing mitochondrial respiration and increasing oxidative stress. Cell Metab. 2007; 6: 280-93.

74. Masoro EJ. Hormesis and the antiaging action of dietary restriction. Exp Gerontol. 1998; 33: 61-6.

75. Harman D. Aging: a theory based on free radical and radiation chemistry. J Gerontol. 1956; 11: 298-300.

76. D'Autréaux B, Toledano MB. ROS as signalling molecules: mechanisms that generate specificity in ROS homeostasis. Nat Rev Mol Cell Biol. 2007; 8: 813-24.

77. Van Raamsdonk JM, Hekimi S. Superoxide dismutase is dispensable for normal animal lifespan. Proc Natl Acad Sci USA. 2012; 109: 5785-90.

78. Shibata Y, Branicky R, Landaverde IO, Hekimi S. Redox regulation of germline and vulval development in Caenorhabditis elegans. Science. 2003; 302: 1779-82.

79. Van Raamsdonk JM, Hekimi S. Deletion of the mitochondrial superoxide dismutase sod-2 extends lifespan in Caenorhabditis elegans. PLoS Genet. 2009; 5: e1000361. doi: 10.1371/journal. pgen.1000361.

80. Yang W, Hekimi S. A mitochondrial superoxide signal triggers increased longevity in Caenorhabditis elegans. PLoS Biol. 2010; 8: e1000556. doi: 10.1371/journal.pbio.1000556.

81. Zarse K, Schmeisser S, Groth M, Priebe S, Beuster G, Kuhlow D, et al. Impaired insulin/IGF1 signaling extends life span by promoting mitochondrial L-proline catabolism to induce a transient ROS signal. Cell Metab. 2012; 15: 451-65.

82. Lee SJ, Hwang AB, Kenyon C. Inhibition of respiration extends C. elegans life span via reactive oxygen species that increase HIF-1 activity. Curr Biol CB. 2010; 20: 2131-6.

83. Yang W, Li J, Hekimi S. A measurable increase in oxidative damage due to reduction in superoxide detoxification fails to shorten the life span of long-lived mitochondrial mutants of Caenorhabditis elegans. Genetics. 2007; 177: 2063-74.

84. Baker BM, Nargund AM, Sun T, Haynes CM. Protective coupling of mitochondrial function and protein synthesis via the eIF $2 \alpha$ kinase GCN-2. PLoS Genet. 2012; 8(6): e1002760. doi: 10.1371/journal. pgen.1002760.

85. Braeckman BP, Houthoofd K, Brys K, Lenaerts I, De Vreese A, Van 
Eygen S, et al. No reduction of energy metabolism in Clk mutants. Mech Ageing Dev. 2002; 123: 1447-56.

86. Kayser EB, Sedensky MM, Morgan PG. The effects of complex I function and oxidative damage on lifespan and anesthetic sensitivity in Caenorhabditis elegans. Mech Ageing Dev. 2004; 125: 455-64.

87. Yang YY, Gangoiti JA, Sedensky MM, Morgan PG. The effect of different ubiquinones on lifespan in Caenorhabditis elegans. Mech Ageing Dev. 2009; 130: 370-6.

88. Labuschagne CF, Stigter ECA, Hendriks MMWB, Berger R, Rokach $\mathrm{J}$, Korswagen $\mathrm{HC}$, et al. Quantification of in vivo oxidative damage in Caenorhabditis elegans during aging by endogenous F3isoprostane measurement. Aging Cell. 2013; 12: 214-23.

89. Petriv OI, Rachubinski RA. Lack of peroxisomal catalase causes a progeric phenotype in Caenorhabditis elegans. J Biol Chem. 2004; 279: 19996-20001.

90. Van Raamsdonk JM, Meng Y, Camp D, Yang W, Jia X, Bénard C, et al. Decreased energy metabolism extends life span in Caenorhabditis elegans without reducing oxidative damage. Genetics. 2010; 185: 559-71.

91. Honda Y, Honda S. The daf-2 gene network for longevity regulates oxidative stress resistance and $\mathrm{Mn}$-superoxide dismutase gene expression in Caenorhabditis elegans. FASEB J Off Publ Fed Am Soc Exp Biol. 1999; 13: 1385-93.

92. Cristina D, Cary M, Lunceford A, Clarke C, Kenyon C. A regulated response to impaired respiration slows behavioral rates and increases lifespan in Caenorhabditis elegans. PLoS Genet. 2009; 5: e1000450. doi: 10.1371/journal.pgen.1000450.

93. Schaar CE, Dues DJ, Spielbauer KK, Machiela E, Cooper JF, Senchuk $\mathrm{M}$, et al. Mitochondrial and cytoplasmic ROS have opposing effects on lifespan. PLOS Genet. 2015; 11: e1004972. doi: 10.1371/journal. pgen.1004972.

94. Wiederkehr A, Wollheim CB. Minireview: implication of mitochondria in insulin secretion and action. Endocrinology. 2006; 147: 2643-9.

95. Ristow M. Oxidative metabolism in cancer growth. Curr Opin Clin Nutr Metab Care. 2006; 9: 339-45.

96. Fukui $\mathrm{H}$, Moraes $\mathrm{CT}$. The mitochondrial impairment, oxidative stress and neurodegeneration connection: reality or just an attractive hypothesis? Trends Neurosci. 2008; 31: 251-6.

97. Tatsuta T, Langer T. Quality control of mitochondria: protection against neurodegeneration and ageing. EMBO J. 2008; 27: 306-14.

98. Bratic A, Larsson NG. The role of mitochondria in aging. J Clin Invest. 2013; 123: 951-7.

99. Trifunovic A, Wredenberg A, Falkenberg M, Spelbrink JN, Rovio AT, Bruder CE, et al. Premature ageing in mice expressing defective mitochondrial DNA polymerase. Nature. 2004; 429: 417-23.

100. Rattan SIS. Hormesis in aging. Ageing Res Rev. 2008; 7: 63-78.

101. Lamming DW, Wood JG, Sinclair DA. Small molecules that regulate lifespan: evidence for xenohormesis. Mol Microbiol. 2004; 53: 1003-9.

102. Yanase S, Hartman PS, Ito A, Ishii N. Oxidative stress pretreatment increases the X-radiation resistance of the nematode Caenorhabditis elegans. Mutat Res. 1999; 426: 31-9.

103. Tapia PC. Sublethal mitochondrial stress with an attendant stoichiometric augmentation of reactive oxygen species may precipitate many of the beneficial alterations in cellular physiology produced by caloric restriction, intermittent fasting, exercise and dietary phytonutrients: "Mitohormesis" for health and vitality. Med Hypotheses. 2006; 66: 832-43.

104. Fontana L, Klein S. Aging, adiposity, and calorie restriction. JAMA. 2007; 297: 986-94.

105. Takemori K, Kimura T, Shirasaka N, Inoue T, Masuno K, Ito H. Food restriction improves glucose and lipid metabolism through Sirt1 expression: a study using a new rat model with obesity and severe hypertension. Life Sci. 2011; 88: 1088-94.

106. He X, Zhao X, Gu Q, Shen J, Hu Y, Hu R. Calorie restriction from a young age preserves the functions of pancreatic $\beta$ cells in aging rats. Tohoku J Exp Med. 2012; 227: 245-52.

107. Harvey AE, Lashinger LM, Otto G, Nunez NP, Hursting SD. Decreased systemic IGF-1 in response to calorie restriction modulates murine tumor cell growth, nuclear factor- $\mathrm{KB}$ activation, and inflammation-related gene expression. Mol Carcinog. 2013; 52: 997-1006.

108. Willette AA, Bendlin BB, Colman RJ, Kastman EK, Field AS, Alexander AL, et al. Calorie restriction reduces the influence of glucoregulatory dysfunction on regional brain volume in aged rhesus monkeys. Diabetes. 2012; 61: 1036-42.

109. Ryan AS, Ortmeyer HK, Sorkin JD. Exercise with calorie restriction improves insulin sensitivity and glycogen synthase activity in obese postmenopausal women with impaired glucose tolerance. Am J Physiol Endocrinol Metab. 2012; 302: E145-52.

110. Larson-Meyer DE, Heilbronn LK, Redman LM, Newcomer BR, Frisard MI, Anton S, et al. Effect of calorie restriction with or without exercise on insulin sensitivity, beta-cell function, fat cell size, and ectopic lipid in overweight subjects. Diabetes Care. 2006; 29: $1337-44$.

111. Heilbronn LK, de Jonge L, Frisard MI, DeLany JP, Larson-Meyer DE, Rood J, et al. Effect of 6-month calorie restriction on biomarkers of longevity, metabolic adaptation, and oxidative stress in overweight individuals: a randomized controlled trial. JAMA. 2006; 295: 153948.

112. Lefevre M, Redman LM, Heilbronn LK, Smith JV, Martin CK, Rood $\mathrm{JC}$, et al. Caloric restriction alone and with exercise improves CVD risk in healthy non-obese individuals. Atherosclerosis. 2009; 203: 206-13.

113. Koizumi A, Weindruch R, Walford RL. Influences of dietary restriction and age on liver enzyme activities and lipid peroxidation in mice. J Nutr. 1987; 117: 361-7.

114. Semsei I, Rao G, Richardson A. Changes in the expression of superoxide dismutase and catalase as a function of age and dietary restriction. Biochem Biophys Res Commun. 1989; 164: 620-5.

115. Rao G, Xia E, Nadakavukaren MJ, Richardson A. Effect of dietary restriction on the age-dependent changes in the expression of antioxidant enzymes in rat liver. J Nutr. 1990; 120: 602-9.

116. Pieri C, Falasca M, Marcheselli F, Moroni F, Recchioni R, Marmocchi $\mathrm{F}$, et al. Food restriction in female Wistar rats: V. Lipid peroxidation and antioxidant enzymes in the liver. Arch Gerontol Geriatr. 1992; 14: 93-9.

117. Youngman LD, Park JY, Ames BN. Protein oxidation associated with aging is reduced by dietary restriction of protein or calories. Proc Natl Acad Sci USA. 1992; 89: 9112-6.

118. Xia E, Rao G, Van Remmen H, Heydari AR, Richardson A. Activities of antioxidant enzymes in various tissues of male Fischer 344 rats are altered by food restriction. J Nutr. 1995; 125: 195-201.

119. Barros MH, Bandy B, Tahara EB, Kowaltowski AJ. Higher respiratory activity decreases mitochondrial reactive oxygen release and increases life span in Saccharomyces cerevisiae. J Biol Chem. 2004; 279: 49883-8.

120. Mahlke MA, Cortez LA, Ortiz MA, Rodriguez M, Uchida K, Shigenaga MK, et al. The anti-tumor effects of calorie restriction are correlated with reduced oxidative stress in ENU-induced gliomas. Pathobiol Aging Age Relat Dis. 2011; 1: 10.3402/pba.v1i0.7189. doi: 10.3402/pba.v1i0.7189.

121. Qiu X, Brown K, Hirschey MD, Verdin E, Chen D. Calorie restriction reduces oxidative stress by SIRT3-mediated SOD2 activation. Cell Metab. 2010; 12: 662-7. 
122. Rippe C, Lesniewski L, Connell M, LaRocca T, Donato A, Seals D. Short-term calorie restriction reverses vascular endothelial dysfunction in old mice by increasing nitric oxide and reducing oxidative stress. Aging Cell. 2010; 9: 304-12.

123. Sreekumar R, Unnikrishnan J, Fu A, Nygren J, Short KR, Schimke $\mathrm{J}$, et al. Effects of caloric restriction on mitochondrial function and gene transcripts in rat muscle. Am J Physiol Endocrinol Metab. 2002; 283: E38-43.

124. Park S, Park NY, Valacchi G, Lim Y. Calorie restriction with a highfat diet effectively attenuated inflammatory response and oxidative stress-related markers in obese tissues of the high diet fed rats. Mediators Inflamm. 2012;2012: 984643. doi: 10.1155/2012/984643.

125. Schmeisser S, Priebe S, Groth M, Monajembashi S, Hemmerich $\mathrm{P}$, Guthke R, et al. Neuronal ROS signaling rather than AMPK/ sirtuin-mediated energy sensing links dietary restriction to lifespan extension. Mol Metab. 2013; 2: 92-102.

126. Beaudart C, McCloskey E, Bruyère $\mathrm{O}$, Cesari M, Rolland Y, Rizzoli $\mathrm{R}$, et al. Sarcopenia in daily practice: assessment and management. BMC Geriatr. 2016; 16: 170. doi: 10.1186/s12877-016-0349-4.

127. Fierro-González JC, González-Barrios M, Miranda-Vizuete A, Swoboda P. The thioredoxin TRX-1 regulates adult lifespan extension induced by dietary restriction in Caenorhabditis elegans. Biochem Biophys Res Commun. 2011; 406: 478-82.

128. Lillig $\mathrm{CH}$, Holmgren A. Thioredoxin and related molecules--from biology to health and disease. Antioxid Redox Signal. 2007; 9: 2547

129. Berndt C, Lillig CH, Holmgren A. Thioredoxins and glutaredoxins as facilitators of protein folding. Biochim Biophys Acta. 2008; 1783: 641-50.

130. Itoh K, Tong KI, Yamamoto M. Molecular mechanism activating Nrf2-Keap1 pathway in regulation of adaptive response to electrophiles. Free Radic Biol Med. 2004; 36: 1208-13.

131. Papaiahgari S, Zhang Q, Kleeberger SR, Cho HY, Reddy SP. Hyperoxia stimulates an Nrf2-ARE transcriptional response via ROS-EGFR-PI3K-Akt/ERK MAP kinase signaling in pulmonary epithelial cells. Antioxid Redox Signal. 2006; 8: 43-52.

132. Kim YC, Masutani H, Yamaguchi Y, Itoh K, Yamamoto M, Yodoi J. Hemin-induced activation of the thioredoxin gene by Nrf2. A differential regulation of the antioxidant responsive element by a switch of its binding factors. J Biol Chem. 2001; 276: 18399-406.

133. Rushmore TH, Morton MR, Pickett CB. The antioxidant responsive element. Activation by oxidative stress and identification of the DNA consensus sequence required for functional activity. J Biol Chem. 1991; 266: 11632-9.

134. Kops GJPL, Dansen TB, Polderman PE, Saarloos I, Wirtz KWA, Coffer PJ, et al. Forkhead transcription factor FOXO3a protects quiescent cells from oxidative stress. Nature. 2002; 419: 316-21.

135. Nemoto S, Finkel T. Redox regulation of forkhead proteins through a p66shc-dependent signaling pathway. Science. 2002; 295: 2450-2.

136. Brunet A, Sweeney LB, Sturgill JF, Chua KF, Greer PL, Lin Y, et al. Stress-dependent regulation of FOXO transcription factors by the SIRT1 deacetylase. Science. 2004; 303: 2011-5.

137. Friedman JR, Kaestner KH. The Foxa family of transcription factors in development and metabolism. Cell Mol Life Sci CMLS. 2006; 63: 2317-28.

138. Panowski SH, Wolff S, Aguilaniu H, Durieux J, Dillin A. PHA-4/ Foxa mediates diet-restriction-induced longevity of C. elegans. Nature. 2007; 447: 550-5.

139. Barger JL, Walford RL, Weindruch R. The retardation of aging by caloric restriction: its significance in the transgenic era. Exp Gerontol. 2003; 38: 1343-51.

140. Smith JV, Heilbronn LK, Ravussin E. Energy restriction and aging.
Curr Opin Clin Nutr Metab Care. 2004; 7: 615-22.

141. Martin B, Mattson MP, Maudsley S. Caloric restriction and intermittent fasting: two potential diets for successful brain aging. Ageing Res Rev. 2006; 5: 332-53.

142. Grundy SM. The optimal ratio of fat-to-carbohydrate in the diet. Annu Rev Nutr. 1999; 19: 325-41.

143. Wijendran V, Hayes KC. Dietary n-6 and n-3 fatty acid balance and cardiovascular health. Annu Rev Nutr. 2004; 24: 597-615.

144. Schulze MB, Hu FB. Primary prevention of diabetes: what can be done and how much can be prevented? Annu Rev Public Health. 2005; 26: 445-67.

145. Heber D. Vegetables, fruits and phytoestrogens in the prevention of diseases. J Postgrad Med. 2004; 50: 145-9.

146. Carpentier YA, Portois L, Malaisse WJ. n-3 fatty acids and the metabolic syndrome. Am J Clin Nutr. 2006; 83 (6 Suppl): 1499S-504S

147. Hu FB, Stampfer MJ. Nut consumption and risk of coronary heart disease: a review of epidemiologic evidence. Curr Atheroscler Rep. 1999; 1: 204-9.

148. Simopoulos AP. The Mediterranean diets: What is so special about the diet of Greece? The scientific evidence. J Nutr. 2001; 131: 3065S-73S.

149. Mattson MP. Dietary factors, hormesis and health. Ageing Res Rev. 2008; 7: 43-8.

150. Johnson JB, Summer W, Cutler RG, Martin B, Hyun D-H, Dixit VD, et al. Alternate day calorie restriction improves clinical findings and reduces markers of oxidative stress and inflammation in overweight adults with moderate asthma. Free Radic Biol Med. 2007; 42: 66574.

151. Heydari AR, Wu B, Takahashi R, Strong R, Richardson A. Expression of heat shock protein 70 is altered by age and diet at the level of transcription. Mol Cell Biol. 1993; 13: 2909-18.

152. Guo Z, Ersoz A, Butterfield DA, Mattson MP. Beneficial effects of dietary restriction on cerebral cortical synaptic terminals: preservation of glucose and glutamate transport and mitochondrial function after exposure to amyloid beta-peptide, iron, and 3-nitropropionic acid. J Neurochem. 2000; 75: 314-20.

153. Ugochukwu NH, Figgers CL. Dietary caloric restriction improves the redox status at the onset of diabetes in hepatocytes of streptozotocininduced diabetic rats. Chem Biol Interact. 2007; 165: 45-53.

154. Hyun DH, Emerson SS, Jo DG, Mattson MP, de Cabo R. Calorie restriction up-regulates the plasma membrane redox system in brain cells and suppresses oxidative stress during aging. Proc Natl Acad Sci USA. 2006; 103: 19908-12.

155. Sanz A, Pamplona R, Barja G. Is the mitochondrial free radical theory of aging intact? Antioxid Redox Signal. 2006; 8: 582-99.

156. Rodgers JT, Lerin C, Haas W, Gygi SP, Spiegelman BM, Puigserver P. Nutrient control of glucose homeostasis through a complex of PGC-1alpha and SIRT1. Nature. 2005; 434: 113-8.

157. Trewavas A, Stewart D. Paradoxical effects of chemicals in the diet on health. Curr Opin Plant Biol. 2003; 6: 185-90.

158. Baur JA, Sinclair DA. Therapeutic potential of resveratrol: the in vivo evidence. Nat Rev Drug Discov. 2006; 5: 493-506.

159. Dinkova-Kostova AT, Holtzclaw WD, Cole RN, Itoh K, Wakabayashi N, Katoh Y, et al. Direct evidence that sulfhydryl groups of Keap1 are the sensors regulating induction of phase 2 enzymes that protect against carcinogens and oxidants. Proc Natl Acad Sci USA. 2002; 99: 11908-13.

160. Balogun E, Hoque M, Gong P, Killeen E, Green CJ, Foresti R, et al. Curcumin activates the haem oxygenase-1 gene via regulation of Nrf2 and the antioxidant-responsive element. Biochem J. 2003; 371: 887-95. 
161. Chen C, Pung D, Leong V, Hebbar V, Shen G, Nair S, et al. Induction of detoxifying enzymes by garlic organosulfur compounds through transcription factor Nrf2: effect of chemical structure and stress signals. Free Radic Biol Med. 2004; 37: 1578-90.

162. Frescas D, Valenti L, Accili D. Nuclear trapping of the forkhead transcription factor FoxO1 via Sirt-dependent deacetylation promotes expression of glucogenetic genes. J Biol Chem. 2005; 280: 20589-95.

163. Mabuchi T, Kitagawa K, Kuwabara K, Takasawa K, Ohtsuki T, Xia Z, et al. Phosphorylation of cAMP response element-binding protein in hippocampal neurons as a protective response after exposure to glutamate in vitro and ischemia in vivo. J Neurosci Off J Soc Neurosci. 2001; 21: 9204-13.

164. Mattson MP, Meffert MK. Roles for NF-kappaB in nerve cell survival, plasticity, and disease. Cell Death Differ. 2006; 13: 852-60.

165. World Health Organization. Global Status Report on Alcohol and Health 2018. Geneva: WHO; 2018.

166. Centers for Disease Control and Prevention (CDC) [Internet]. Alcohol and Public Health: Alcohol-Related Disease Impact (ARDI) [cited 2020 May 13]. Available from: https://nccd.cdc.gov/DPH_ARDI/ default/default.aspx.

167. Stahre M, Roeber J, Kanny D, Brewer RD, Zhang X. Contribution of excessive alcohol consumption to deaths and years of potential life lost in the United States. Prev Chronic Dis. 2014; 11: E109. doi: $10.5888 /$ pcd11.130293.

168. Sacks JJ, Gonzales KR, Bouchery EE, Tomedi LE, Brewer RD. 2010 National and state costs of excessive alcohol consumption. Am J Prev Med. 2015; 49: e73-9.

169. Fernández-Solà J. Cardiovascular risks and benefits of moderate and heavy alcohol consumption. Nat Rev Cardiol. 2015; 12: 576-87.

170. Mukamal KJ, Rimm EB. Alcohol consumption: risks and benefits.
Curr Atheroscler Rep. 2008; 10: 536-43.

171. Stampfer MJ, Colditz GA, Willett WC, Speizer FE, Hennekens CH. A prospective study of moderate alcohol consumption and the risk of coronary disease and stroke in women. N Engl J Med. 1988; 319 : 267-73.

172. Roerecke M, Rehm J. The cardioprotective association of average alcohol consumption and ischaemic heart disease: a systematic review and meta-analysis. Addict Abingdon Engl. 2012; 107: 124660.

173. Roerecke M, Rehm J. Alcohol consumption, drinking patterns, and ischemic heart disease: a narrative review of meta-analyses and a systematic review and meta-analysis of the impact of heavy drinking occasions on risk for moderate drinkers. BMC Med. 2014; 12: 182. doi: 10.1186/s12916-014-0182-6.

174. Ronksley PE, Brien SE, Turner BJ, Mukamal KJ, Ghali WA. Association of alcohol consumption with selected cardiovascular disease outcomes: a systematic review and meta-analysis. BMJ. 2011; 342: d671. doi: 10.1136/bmj.d671.

175. O'Keefe JH, Bybee KA, Lavie CJ. Alcohol and cardiovascular health: the razor-sharp double-edged sword. J Am Coll Cardiol. 2007; 50: 1009-14.

176. Krenz M, Korthuis RJ. Moderate ethanol ingestion and cardiovascular protection: from epidemiologic associations to cellular mechanisms. J Mol Cell Cardiol. 2012; 52: 93-104.

177. Perissinotto E, Buja A, Maggi S, Enzi G, Manzato E, Scafato E, et al. Alcohol consumption and cardiovascular risk factors in older lifelong wine drinkers: The Italian Longitudinal Study on Aging. Nutr Metab Cardiovasc Dis. 2010; 20: 647-55.

178. Wakabayashi I. Associations between alcohol drinking and multiple risk factors for atherosclerosis in smokers and nonsmokers. Angiology. 2010; 61: 495-503. 